\title{
Analisis Kinerja Rantai Pasok Ikan Nila Pada Bandar Sriandoyo Kecamatan Tugumulyo Kabupaten Musi Rawas: Pendekatan Food Supply Chain Networks (FCSN) \\ Supply Chain Performance Analysis of Tilapia Fish in Bandar Sriandoyo in Tugumulyo District of Musi Rawas Regency : Food Supply Chain Networks (FCSN) Approach

\author{
${ }^{* 1)}$ Setiadi, ${ }^{2)}$ Rita Nurmalina, ${ }^{3)}$ Suharno \\ *1,2,3 Departemen Agribisnis, Fakultas Ekonomi Manajamen, Institut Pertanian Bogor

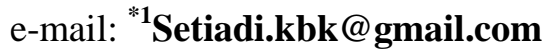

\begin{abstract}
Supply chain network of tilapia products, which is run by Bandar Sriandoyo as a business unit engaged in the marketing and distribution of tilapia fish in partnership with tilapia fish farmers in Tugumulyo District Musi Rawas Regency, has a goal to meet some of the needs of tilapia products for consumers in region of South Sumatera Province. The model of supply chain of indigo fish in Musi Rawas Regency is discussed descriptively by using development method following Food Supply Chain Networks (FSCN) process framework. The results showed that the supply chain of tilapia fish at Bandar Sriandoyo in Tugumulyo District of Musi Rawas Regency based on FSCN approach involves supply chain members consisting of partner farmers, Bandar Sriandoyo, bakul (wholesalers), and retailers. The flow patterns of goods, financial flows, and the flow of information have generally been relatively good. In particular, the dynamic flow of information becomes an important factor in the running of business processes and collaborative planning, as well as building trust among the members of the indigo fish supply chain.
\end{abstract}

Keywords: FSCN, Supply Chain, Tilapia

\section{Pendahuluan}

Indonesia merupakan negara yang dikaruniai potensi sumber daya yang melimpah serta dukungan pola iklim yang baik, sehingga sangat potensial untuk pengembangan sektor perikanan. Sejalan dengan pertumbuhan penduduk dan perekonomian Indonesia, serta kesadaran masyarakat akan konsumsi ikan semakin tinggi, ditambah lagi dengan adanya program Gemar Makan Ikan (Gemarikan) yang dikampanyekan Kementerian Kelautan dan Perikanan (KKP), angka konsumsi ikan terus naik. Sebagaimana yang dikutip dari KKP (2016) bahwa trend konsumsi ikan selama tahun 2011-2015 menunjukkan peningkatan sebesar 6.27 persen. Pada tahun 2016 tercatat tingkat konsumsi ikan nasional sebanyak $43.94 \mathrm{~kg}$ per kapita per tahun (Cocon 2017). Untuk memenuhi kebutuhan permintaan produk ikan yang besar, maka KKP membuat program industrialisasi perikanan, salah satunya adalah pada sektor perikanan budidaya dengan mengangkat komoditas ikan nila sebagai komoditas unggulan. Atas dasar pertimbangan bahwa volume dan nilai produksi maupun ekspor ikan nila merupakan yang tertinggi diantara komoditas perikanan budidaya lainnya. Hal ini menunjukkan ikan nila memiliki potensi yang sangat strategis.

Pemenuhan kebutuhan ikan nila bagi konsumen tidak terlepas dari sistem manajemen rantai pasok. Menurut Chopra dan Meindhl (2007) bahwa manajemen rantai pasok adalah keterpaduan antara perencanaan, koordinasi, dan kendali seluruh proses dan aktivitas bisnis dalam rantai pasok untuk memenuhi kebutuhan konsumen dengan biaya yang paling rendah.

Received August $9^{\text {th }}$, 2017; Revised August 25 ${ }^{\text {th }}$,20xx; Accepted September 10 ${ }^{\text {th }}, 2017$ 
Rantai pasok lebih ditekankan pada segi aliran dan transformasi produk, aliran informasi dan keuangan dari tahapan bahan baku sampai pada pengguna akhir (Handfield et al 2012).

Komoditas ikan nila merupakan bagian dari komoditas pertanian yang dalam perkembangan rantai pasoknya memiliki keunikan dari karakteristik produksi dan aliran produk. Karakteristik produk pertanian yang mudah rusak, budidaya dan pemanenan sangat tergantung iklim dan musim, kualitas yang bervariasi, dan bersifat kamba, yakni terdapat beberapa produk sangat sulit diangkut dan dikelola sebab ukuran dan kompleksitas dari produknya (Marimin dan Magfiroh 2010).

Jaringan rantai pasok produk ikan nila salah satunya adalah yang dijalankan oleh Bandar Sriandoyo sebagai unit bisnis yang bergerak dibidang pemasaran dan distribusi ikan nila yang bermitra dengan pembudidaya ikan nila di Kecamatan Tugumulyo Kabupaten Musi Rawas yang mempunyai tujuan untuk memenuhi sebagian kebutuhan produk ikan nila bagi konsumen di wilayah Provinsi Sumatera Selatan. Namun dalam pengelolaan rantai pasok masih mengalami kendala dalam ketepatan waktu maupun jumlah dan kualitas yang dibutuhkan konsumen. Salah satu penyebabnya adalah dalam proses produksi budidaya ikan nila relatif masih dipengaruhi oleh faktor cuaca/iklim, sehingga terdapat kelemahan dalam memprediksi waktu dan hasil panen. Selain itu faktor teknis dalam penanganan pemanenan dan pasca panen yang kurang tepat, serta jarak yang jauh dari lokasi pembudidaya ke lokasi pemasaran, berdampak pada kualitas produk dan waktu pemenuhan pesanan bagi konsumen. Selain itu produk ikan nila yang dipasarkan dalam bentuk segar hidup yang bersifat mudah rusak (high perishable) sehingga memiliki potensi yang tinggi terjadinya resiko kerugian dalam setiap tahapan rantai pasok. Hal tersebut mengindikasikan adanya permasalahan dalam rantai pasok ikan nila. Oleh karena itu penelitian dilakukan untuk menjawab beberapa permasalahan tersebut. Adapun tujuan dari penelitian ini yaitu mengidentifikasi rantai pasok ikan nila pada Bandar Sriandoyo Kecamatan Tugumulyo Kabupaten Musi Rawas, dan menganalisis efisiensi kinerja rantai pasok ikan nila pada Bandar Sriandoyo di Kecamatan Tugumulyo Kabupaten Musi Rawas.

\section{Metode}

Penelitian ini dilakukan pada satu satu unit bisnis yaitu Bandar Sriandoyo yang bermitra dengan 38 pembudidaya ikan nila di Kecamatan Tugumulyo Kabupaten Musi Rawas Provinsi Sumatera Selatan. Pemilihan lokasi penelitian dilakukan secara sengaja (purposive sampling) dengan pendekatan studi kasus. Berdasarkan pertimbangan bahwa tempat penelitian merupakan salah satu sentra produksi budidaya ikan nila di Kabupaten Musi Rawas. Penelitian ini dilaksanakan pada bulan Mei sampai dengan Juni 2017.

Jenis data yang digunakan dalam penelitian ini terdiri dari data primer dan data sekunder, baik yang bersifat kuantitatif maupun kualitatif. Data primer diperoleh dari wawancara mendalam (indept interview) dengan pelaku rantai pasok ikan nila dan observasi atau pengamatan secara langsung di lokasi penelitian. Sedangkan data sekunder diperoleh melalui literatur, data-data dari lembaga-lembaga pemerintah dan instansi terkait dalam penelitian ini. Responden dalam ppenelitian ini adalah Bandar Sriandoyo dan 2 bandar lainnya, pembudidaya mitra, bakul (pedagang besar), dan pedagang pengecer.

rantai pasok ikan nila di Kabupaten Musi Rawas dibahas secara deskriptif dengan menggunakan metode pengembangan mengikuti kerangka proses Food Supply Chain Networks (FSCN) dari Lambert et al (2001) yang dimodifikasi oleh Van Der Vorst (2006) sebagaimana dapat dilihat pada Gambar 1. Kerangka FSCN terdiri dari struktur rantai pasok, manajemen rantai pasok, sumber daya rantai pasok, dan proses bisnis rantai pasok.

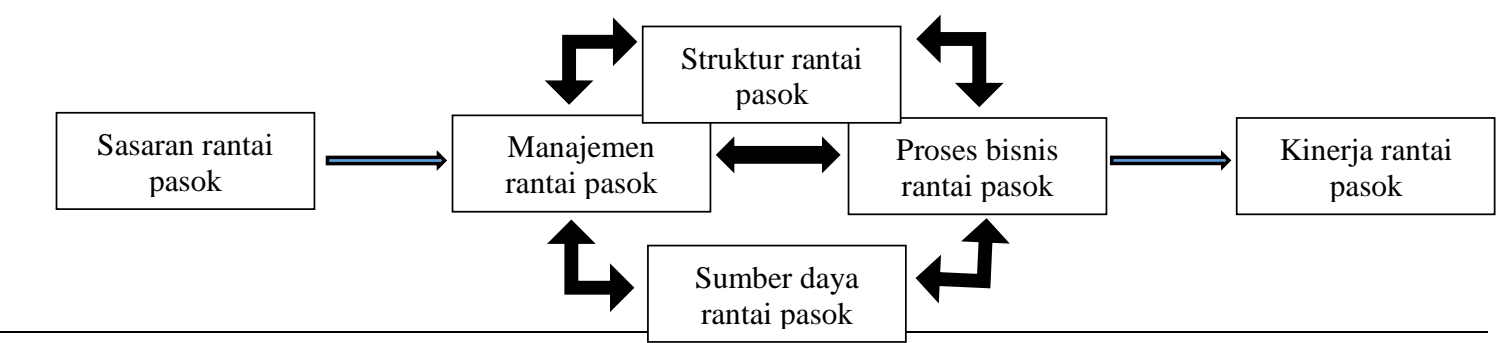

Analisis Kinerja Rantai Pasok Ikan Nila pada Bandar Sriandoyo (Setiadi) 
Gambar 1 Kerangka analisis deskriptif rantai pasok ikan nila dengan pendekatan FSCN Sumber: Van Der Vorst (2006)

\section{Hasil dan Pembahasan}

\section{Analisis Deskriptif Rantai Pasok Ikan Nila dengan pendekatan FSCN}

\section{Sasaran Rantai Pasok Ikan Nila Sasaran Pasar}

Ikan nila yang dihasilkan oleh pembudidaya mitra dan Bandar Srandoyo di Kecamatan Tugumulyo Kabupaten Musi Rawas adalah ikan untuk konsumsi dengan kisaran ukuran 125 300 gram per ekor (3-8 ekor per kilogram) dalam bentuk ikan segar hidup. Adapun pemasarannya adalah untuk pemenuhan kebutuhan konsumen lokal atau dalam daerah Provinsi Sumatera Selatan yakni Kota Palembang dan Kabupaten Muara Enim.

\section{Sasaran Pengembangan}

Permintaan ikan nila terus meningkat dan peluang pasar yang masih terbuka, maka Bandar Sriandoyo bersama pembudidaya mitra berupaya melakukan pengembangan produksi ikan nila dengan cara intensifikasi dan ekstensifikasi budidaya ikan nila. Selain itu menjajaki peluang pengembangan pemasaran ikan nila di daerah lain dalam wilayah Provinsi Sumatera Selatan.

\section{Manajemen Rantai Pasok Ikan Nila Pemilihan Mitra}

Pembudidaya ikan nila tidak menetapkan kriteria khusus dalam memilih mitra untuk memasarkan hasil produksinya. Kerjasama dibangun atas dasar saling percaya, saling membutuhkan serta saling menguntungkan. Begitu juga dengan Bandar Sriandoyo tidak menetapkan kriteria khusus dalam memilih pembudidaya mitra. Namun pertimbangan utama dalam memilih pembudidaya mitra adalah kriteria teknis yaitu pembudidaya mitra harus memiliki kolam budidaya didukung oleh sumber air yang baik dari segi kuantitas maupun kualitasnya Begitu juga dalam memilih pemasar atau bakul (pedagang besar) tidak ada kriteria khusus, namun tetap berdasarkan prinsip saling percaya, transparansi informasi pasar dan komitmen menjaga kerjasama jangka panjang yang saling menguntungkan. Sejalan dengan Qhoirunisa (2014) bahwa pemilihan mitra adalah proses memilih rekan kerja untuk dapat bekerja sama dalam suatu usaha. Kinerja mitra yang dipilih oleh anggota rantai pasok akan menentukan suatu usaha dan dalam rangka mencapai tujuan rantai pasok yaitu memenuhi kepuasan konsumen, maka diperlukan pemilihan mitra sesuai kebutuhan anggota rantai pasok.

\section{Kesepakatan Kontraktual}

Kesepakatan kontraktual dalam kerjasama antara Bandar Sriandoyo dengan Pembudidaya mitra dilakukan secara informal atau tidak tertulis. Namun secara tersirat adanya kesepakatan antara pembudidaya mitra dengan Bandar Sriandoyo diantranya yaitu pembudidaya mitra harus menjual hasil budidaya ikan nila kepada Bandar Sriandoyo, pihak Bandar Sriandoyo akan memenuhi kebutuhan pakan bagi pembudidaya mitra dalam bentuk pinjaman pakan (pelet) yang dibayar pada saat setelah mendapatkan hasil panen. Penentuan harga ikan nila oleh pihak Bandar Sriandoyo disesuaikan dengan kualitas ikan nila dan harga pasar. Begitu juga kesepakatan antara Bandar Sriandoyo dengan pihak bakul (pedagang besar) juga dilakukan secara informal. Kesepakatan tersebut berupa kesepakatan tentang pembayaran dan penentuan harga disesuaikan dengan kualitas ikan nila dan harga pasar yang berlaku saat tersebut. 


\section{Struktur Rantai Pasok Ikan Nila}

Anggota Primer Rantai Pasok Ikan Nila

Anggota primer adalah pihak-pihak yang terlibat secara langsung dalam kegiatan bisnis rantai pasok. Susunan dan aktivitas anggota primer rantai pasok ikan nila (Tabel 1).

Tabel 1 Aktivitas anggota primer rantai pasok ikan nila

\begin{tabular}{|c|c|c|c|c|c|}
\hline & \multirow[b]{2}{*}{ Aktivitas } & \multicolumn{4}{|c|}{ Anggota primer rantai pasok ikan nila } \\
\hline & & Pembudidaya & $\begin{array}{l}\text { Bandar } \\
\text { Sriandoyo }\end{array}$ & Bakul & $\begin{array}{l}\text { Pedagang } \\
\text { Pengecer }\end{array}$ \\
\hline \multirow{2}{*}{ Pertukaran } & Penjualan & $\sqrt{ }$ & $\sqrt{ }$ & $\sqrt{ }$ & $\sqrt{ }$ \\
\hline & Pembelian & - & $\sqrt{ }$ & $\sqrt{ }$ & $\sqrt{ }$ \\
\hline \multirow[t]{5}{*}{ Fisik } & Budidaya & $\sqrt{ }$ & - & - & - \\
\hline & Pemanenan & $\sqrt{ }$ & $\sqrt{ }$ & - & - \\
\hline & Pengemasan & - & $\sqrt{ }$ & $\sqrt{ }$ & $\sqrt{ }$ \\
\hline & Pengangkutan & - & $\sqrt{ }$ & $\sqrt{ }$ & $\sqrt{ }$ \\
\hline & Penyimpanan & - & - & $\bullet$ & $\bullet$ \\
\hline \multirow[t]{4}{*}{ Fasilitas } & Sortasi & - & - & $\sqrt{ }$ & - \\
\hline & Garading & - & - & $\sqrt{ }$ & - \\
\hline & Informasi Pasar & $\sqrt{ }$ & $\sqrt{ }$ & $\sqrt{ }$ & $\sqrt{ }$ \\
\hline & Financing & - & $\sqrt{ }$ & - & - \\
\hline
\end{tabular}

Keterangan : $(\sqrt{ })$ : Dilakukan; $(-)$ : Tidak dilakukan; $(\bullet)$ : Kadang-kadang dilakukan

\section{Anggota Sekunder Rantai Pasok Ikan Nila}

Anggota sekunder rantai pasok adalah yang memperlancar kegiatan rantai pasok dalam menyediakan barang/jasa yang dibutuhkan diantaranya kebutuhan input produksi, seperti benih, pupuk, kapur pertanian, obat-obatan, dan peralatan/saprokan (sarana produksi ikan) bagi pembididaya mitra, juga kebutuhan pasca panen oleh bandar Sriandoyo seperti kebutuhan kantong plastik pengemasan, tabung oksigen, dan lain-lain. Hubungan antara pembudidaya maupun Bandar (pengumpul) dengan pemasok barang-barang input produksi serta kebutuhan pasca panen hanya sebatas hubungan sebagai konsumen biasa dan tidak ada kerjasama secara khusus. Terkecuali untuk pengadaan pakan (pelet), Bandar Sriandoyo melakukan kerjasama secara khusus dengan distributor pakan (pelet) pabrik dalam pemenuhan kebutuhan pakan bagi pembudidaya mitranya. 


\section{Proses Bisnis Rantai Pasok Ikan Nila \\ Hubungan proses bisnis rantai pasok ikan nila}

Rantai pasok ikan nila hanya terdapat tiga siklus, yaitu procurement, replenishment, dan customer order. Sedangkan siklus manufacturing tidak terdapat dalam rantai pasok ikan nila karena tidak melibatkkan anggota rantai pasok yang berperan sebagai pengolah langsung. Proses bisnis yang terjadi pada Bandar Sriandoyo mengarah pada proses pull dan push. Proses pull terjadi pada siklus replenishment misalnya menambah jumlah pesanan dari jumlah pesanan sebenarnya, sebagai antisipasi jika terjadi pemesanan tambahan dari konsumen atau jika terjadi kerusakan atau kematian pada ikan nila tersebut. Proses push terjadi pada sikus procurement dimana pengadaan bahan baku (ikan nila) didasarkan atas respon real permintaan konsumen.

\section{Pola distribusi}

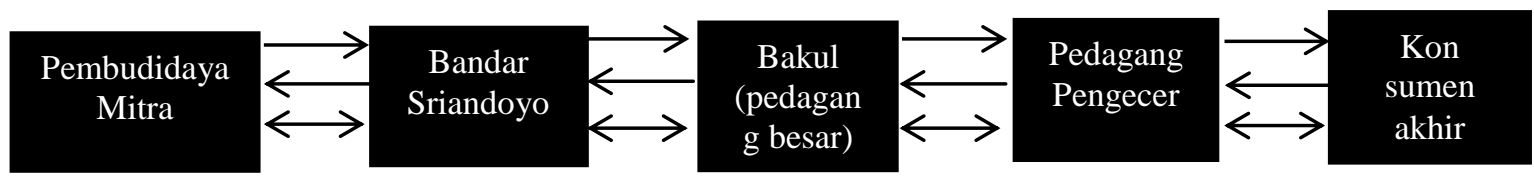

Gambar 3 Pola aliran produk rantai pasok ikan nila

Keterangan $: \longrightarrow$ Aliran Produk $\longleftrightarrow$ Aliran Finansial $\longleftrightarrow \longleftrightarrow$ Aliran Informasi

Pujawan (2005) mengatakan bahwa terdapat tiga macam pola distribusi yang harus dikelola dalam rantai pasok, yakni aliran barang, aliran uang (finansial) dan aliran informasi. Pola distribusi barang mengalir dari hulu (upstream) ke hilir (downstream), sedangkan aliran uang (finansial) mengalir sebaliknya dari hilir ke hulu. Sedangkan pola aliran informasi mengalir dari hulu ke hilir dan sebaliknya. Pola aliran produk ikan nila mulai dari pembudidaya mitra hingga ke konsumen akhir. Ikan nila pada kolam pembudidaya dilakukan proses pemanenan oleh Bandar Sriandoyo kemudian ditimbang dan dilakukan proses pengemasan sesuai jumlah permintaan konsumen, selanjutnya ikan nila dikirim kepada bakul (pedang besar) di Kota Palembang dan Kabupaten Muara Enim. Oleh bakul dilakukan sortasi yaitu memisahkan ikan yang mati dengan yang masih segar hidup, grading dilakukan untuk memisahkkan ikan berdasarkan ukuran. Selanjutnya oleh bakul ikan dijual kepada pedagang pengecer yang membuka lapak di pasar-pasar tradisional.

Aliran uang (finansial) dalam rantai pasok ikan nila akan mengalir dari hilir ke hulu. Konsumen membayar ikan nila secara langsung secara tunai ke pedagang pengecer. Pembayaran dari pedagang pengecer kepada Bakul (pedagang besar) dilakukan dengan cara kredit dengan tempo satu hari. Begitu juga Bakul (pedagang besar) membayar kepada Bandar Sriandoyo secara kredit, yaitu dengan tempo waktu pembayaran dengan cara tiga sampai empat nota hutang/pengiriman ikan nila, kemudian dibayar setelah tujuh hari terhitung dari nota hutang pertama. Sedangkan pembayaran dari Bandar Sriandoyo kepada pembudidaya mitra dilakukan 5-7 hari setelah semua ikan nila di kolam habis total terjual.

Aliran informasi yang terjadi dalam rantai pasok ikan nila mengalir dari hilir ke hulu, dimana konsumen mengkomunikasikan perihal pesanan ikan nila sesuai dengan jumlah, kualitas, serta waktu yang diinginkan melalui bakul kepada Bandar Sriandoyo dan sampai ke pembudidaya mitra. Aliran informasi juga terjadi hulu ke hilir. Dimana pembudidaya mitra menyampaikan informasi perihal kondisi perkembangan ikan nila selama pemeliharaan kepada Bandar Srandoyo. Bandar Sriandoyo mengalirkan informasi kepada Bakul (pedagang besar) ketersediaan stok ikan nila, kondisi kualitas ikan nila dan status pengiriman. Begitu juga dari pihak bakul (pedagang besar) akan mengkonfirmasi kepada Bandar Sriandoyo perihal status barang (ikan nila) yang sudah diterima apakah sesuai dengan kualitas, ukuran dan jumlahnya. Sejauh ini pola aliran rantai pasok diantara anggota rantai pasok telah terintegrasi cukup baik. Sejalan dengan Supriatna et al (2016) bahwa struktur rantai pasok yang terintegrasi baik dari hulu ke hilir maupun sebaliknya akan mempengaruhi kinerja dan kolaborasi rantai pasok. 


\section{Perencanaan Kolaboratif}

Sebagaimana pada penjelasan pola aliran informasi diatas menunjukkan adanya kolaborasi diantara anggota rantai pasok ikan nila, karena terjadi komunikasi dan koordinasi diantara anggota rantai pasok dalam rangka memenuhi kebutuhan ikan nila bagi konsumen dengan sebaik mungkin. Sejalan dengan yang dikatakan Collins dan Dunne (2002) bahwa kolaborasi dan koordinasi dalam menyebarkan informasi yang akurat dan dapat dipercaya diperlukan untuk menciptakan komunikasi yang efektif. keterbukaan informasi menjadi awal terciptanya hubungan baik antar pelaku rantai pasok, sehingga dapat menjadi indikator tingkat efisiensi rantai pasok.

\section{Proses Membangun Kepercayaan}

Proses membangun kepercayaan, tidak terlepas dari membangun komunikasi seperti dijelaskkan pada pola aliran informasi di atas. Menurut Collins dan Dunne (2002) hubungan yang baik perlu dilakukan oleh setiap pelaku rantai pasok untuk mencapai keberhasilan kesatuan rantai pasok. Hubungan yang dimaksud berupa keterbukaan dan kejujuran dalam informasi untuk menghindari asymetric information.

\section{E. Sumber Daya Rantai Pasok Sumber Daya Fisik}

Sumber daya fisik yang dimiliki oleh oleh pembudidaya mitra yang utama antara lain kolam budidaya, sarana produksi budidaya (input produksi), dan sarana transportasi untuk mengangkut input produksi. Sumber daya fisik yang dimiliki Bandar Sriandoyo antara lain peralatan pemanenan, peralatan pengemasan (packaging), juga sarana pengangkutan/distribusi berupa kendaraan roda dua dan roda empat, gudang peralatan, serta rumah sekaligus tempat urusan administrasi. Selain itu terdapat infrastruktur pendukung diantaranya jaringan irigasi sebagai sumber air bagi budidaya ikan nila, jalan untuk akses transportasi dan distribusi, jaringan listrik dan jaringan komunikasi sudah tersedia cukup baik.

\section{Sumber Daya Teknologi}

Sistem teknologi budidaya ikan nila yang diterapkan oleh pembudidaya mitra adalah teknik budidaya pembesaran ikan nila secara intensif di kolam air tenang dan kolam semi air deras. Bandar Sriandoyo menerapkan sistem pemanenan secara bertahap, teknik pengangkutan dengan sistem tertutup yaitu dengan pengemasan menggunakan kantong plastik yang disi media air, oksigen dan batu es. Pendistribusian dengan menggunakan kendaraan roda empat bak terbuka yang dimodifikasi khusus untuk mengangkut/distribusi ikan nila.

\section{Sumber Daya Manusia}

Kegiatan budidaya ikan nila dilakukan oleh pembudidaya mitra sendiri dan dibantu oleh keluarganya. Bandar Sriandoyo memiliki tenaga kerja berjumlah 18 orang pegawai harian tetap dan 1 orang bagian admistrasi dengan gaji bulanan. Pembagian kerjanya meliputi bagian pemanenan berjumlah 5 orang, bagian pengemasan (packaging) berjumlah 6 orang dan bagian pengiriman 6 orang. Seluruh pembudidaya mitra dan pegawai yang dipekerjakan oleh Bandar Sriandoyo berasal dari daerah Kecamatan Tugumulyo.

\section{Sumber Daya Modal}

Permodalan pembudidaya mitra pada umumnya menggunakan modal sendiri untuk membeli input produksi budidayanya, terkecuali khusus modal pengadaan pakan berasal dari pinjaman Bandar Sriandoyo. Pembudidaya ikan nila tidak melakukan peminjaman modal di lembaga keuangan seperti perbankan, dengan alasan karena sulitnya persyaratan yang diajukan oleh pihak perbankan terutama syarat harus memiliki agunan sebagai jaminan. 


\section{Simpulan}

Kondisi rantai pasok ikan nila pada Bandar Sriandoyo di Kecamatan Tugumulyo Kabupaten Musi Rawas berdasarkan pendekatan FSCN melibatkan anggota rantai pasok terdiri dari pembudidaya mitra, Bandar Sriandoyo, bakul (pedagang besar), dan pedagang pengecer. Pola aliran barang, aliran finansial, dan aliran informasi secara umum telah berjalan relatif baik. Terutama aliran informasi yang terjadi secara dinamis menjadi faktor penting berjalannya proses bisnis dan perencanaan kolaboratif, serta terbangunnya kepercayaan diantara anggota rantai pasok ikan nila.

\section{Daftar Pustaka}

Chopra S, Meindehl P. 2007. Supply Chain Management : Strategy, Planning, and Operation. New Jersey (US) :Pearson Prentice Hall.

Cocon. 2017. Nilai Strategis Perikanan Budidaya dalam Menopang Ketahanan Pangan. [internet]. [diunduh pada tanggal 1 Agustus 2017]. Tersedia pada http://ekonomi.kompas.com/read/2017/07/24/161733226/nilai-strategiis-perikananbudidaya-dalam-menopang-ketahanan-pangan

Collins, Dunne. 2002. Farming and Managing Supply Chain in Agribusiness: Learning From Others. Departement Of Agriculture. Forestry and Fisheries. Canberra

Handfield RB, Ernest L, Nichols Jr. 2012. Supply Chain Redesign. New Jersey (US):Prentice Hall.

[KKP] Kementerian Kelautan dan Perikanan. 2016. Konsumsi ikan naik dalam 5 tahun terakhir.[internet].[diunduh pada tanggal 12 Januari 2017]. Tersedia pada http://kkp.go.id/wp-content/uploads/2016/05/Konsumsi-Ikan-Naik-dalam-5-TahunTerakhir.pdf

Pujawan IN. 2005. Supply Chain Management. Surabaya (ID): Guna Widya.

Qhoirunisa A. 2014. Rantai Pasok Padi di Kabuaten Bogor Jawa Barat. [tesis]. Bogor (ID): IPB

Supriatna DC, Perdana T, Noor TI. 2016. Struktur Rantai Pasok pada Kluster Sayuran Untuk Tujuan Pasar Terstruktur. Jurnal Arikultura. 27(1):102-111.

Van Der Vorst. 2006. Performance Measurement in Agri-Food Supply Chain Networks. Netherlands (NLD): Logistics and Operations Research Group, Wageningen University. 